\title{
ICT TOOLS FOR TACKLING BULLYING IN SCHOOLS: AN ANALYSIS AND OPPORTUNITIES
}

\author{
Juan M. Alberola ${ }^{1,2}$, Víctor Sanchez-Anguix ${ }^{1,2}$, María D. Soto-González ${ }^{3}$, Sandra \\ Molines Borrás ${ }^{1}$, Gonzalo Monfort Torres ${ }^{1}$, Susana Díaz Novillo ${ }^{1}$ \\ ${ }^{1}$ Florida Universitària (SPAIN) \\ ${ }^{2}$ Universitat Politècnica de València (SPAIN) \\ ${ }^{3}$ Universitat de València (SPAIN)
}

\begin{abstract}
Bullying is defined as the act of repeatedly and intentionally causing harm to another person who feels helpless (i.e., the victim) against the perpetrator or group of perpetrators. These series of acts of physical and/or psychological violence have been reported to cause a negative impact on the victim on several aspects of his/her well-being and daily life. Recently, multidisciplinary research teams have noticed the potential of ICT tools as catalysts for fighting bullying in schools. A range of ICT-based tools such as elearning systems, intelligent tutoring systems, gamified applications, analytics, or even artificial intelligence have been proposed as technological assets against bullying. In this paper, we identify, categorize, and analyse the use of these ICT tools against bullying under a wide range of criteria such as their role (e.g., prevention, mitigation, detection, etc.), the potential investment that is required, the target age of users, and strengths and weaknesses of each tool. Then, we discuss on potential areas of expansion for the use of ICT tools in the fight bullying, and we identify new potential areas of research.
\end{abstract}

Keywords: Research on Technology in Education, Apps for education, bullying, ICT, school, barriers to learning.

\section{INTRODUCTION}

Ensuring an optimal development of cognitive, emotional, and social skills is one of the aims of education. In the last few years we have seen an increasing interest on tackling bullying at schools. In fact, violence has been acknowledged as an important problem at both the national and the European Commission. The rise of social networks as a daily tool has resulted in changes in the ways that we communicate with our peers, as well as the ways in which violence is exerted. In fact, new technologies are a new tool for bullies that allows them to ignore space and time, making it more threatening for victims [2]. Given this scenario, it is now more crucial to work across the educational system on bullying prevention, detection and mitigation strategies. This work should be independent of the stage in the educational system, since identifying bullying among peers is possible even at early ages [3]

Research on bullying has been active in the last few years. Traditionally, studies have focused on determining the causes and effects of bullying on victims, the role of witnesses, or they have focused on profiling perpetrators. Due to these efforts, we now have a clearer picture on the role of victims, witnesses, and perpetrators. Despite these efforts, there are still variables and factors whose effects on any of the three players we have not yet determined, and questions that remain unanswered.

As Information and Communication Tools (ICT) have emerged as part of our day to day lives, multidisciplinary teams have proposed the use of these technologies as potential detection, prevention and mitigation actors against bullying. In fact, A range of ICT-based tools such as e-learning systems, intelligent tutoring systems, gamified applications, analytics, or even artificial intelligence have been proposed as technological assets against bullying. In this paper, first we discuss the problem of bullying at schools. Then, we identify, categorize, and analyse the use of these ICT tools against bullying under a wide range of criteria such as their role (e.g., prevention, mitigation, detection, etc.), the potential investment that is required, the target age of users, the place at which these tools are meant to be used, and strengths and weaknesses of each tool. Finally, we discuss potential areas of expansion for the use of ICT tools in the fight bullying, and we identify new potential areas of research. 


\section{BULLYING}

Both the educational culture and its regulations have been giving more and more importance to school coexistence, establishing it as an objective of education. Coexistence in educational centers leads to situations of great complexity insofar as it is the pillar of all common activities. Living together requires an indispensable analysis and understanding of the educational fact. The teaching staff together with the management teams, as well as the school councils of the educational centers, as well as the family associations have a key role in the management of coexistence, a professional and personal challenge, as a team, and a vital line that is essential since it manages to establish in a very important way the dynamics that determine it and undoubtedly the effectiveness of the training that is provided there.

It is rational for schools to need a link between the teaching-learning process and the set of interpersonal relationships that are born in everyday life. Emotions, values and feelings of the students; qualities, attitudes and behaviors of the teachers; communication with the families, are processes that organize the basis of what we understand by coexistence [4]. In educational institutions, there are social problems that affect coexistence. From conflicts and communication difficulties, to discipline and disruption problems, to harassment and mistreatment among schoolchildren such as bullying.

Bullying has had many definitions since it became the focus of research in the different scientific disciplines in the 1970s. Firstly, research used multiple criteria to assess the phenomenon of bullying among peers, such as the roles of the students involved, the typology of the aggression or the elements that affect it [5]. The peak of research on school bullying took place between the 1980s and 1990s, transcending numerous countries such as the UK, Norway, the Netherlands, Japan and Spain [6].

The term bullying was defined by Dan Olweus, as a type of violence that is represented by a repeated violent behaviour towards the same person, involving attacks at both the physical and psychological levels, with inequality between the person who attacks and his or her victim, and with intentionality from the person who attacks to do harm [7]. In schools, the effects of bullying range from anxiety, decrease of self-esteem, depressive conditions, to a decrease in the integration of the victim in the school environment and the development of learning [8]. In some situations, the effects of bullying are even prevalent in adulthood.

Another important issue for our research is that, in bullying scenarios, we find other agents besides the victims and aggressors, a representation of agents whose scope is both direct and indirect. The author in [9] points out that bullying commonly occurs in contexts where numerous members of the peer group are present, and, therefore, it highlights the importance of the witnesses, who will adopt one role or another depending on personal and contextual factors.

Researchers have tried to approach the problem from various angles, and one of them is finding out what the motivation of the stalker is. One rather enlightening concept, explained in the early 1990s, is that bullying is unprovoked, deliberate, proactive and purposeful behavior [10]. Proactivity in bullying has led to the idea that bullies are not necessarily socially unskilled, maladjusted or emotionally unstable people, but can use aggression quite skillfully to achieve their goals [11]. It has been suggested that bullying behavior is motivated by the bullies' pursuit of high status and a powerful, dominant position in the peer group [12].

Although it is an individual motive, the pursuit of status is clearly related to the group. It should be noted that it is the group that assigns status to its members, so bullies depend on it. This makes the network that individuals form a system of relationships of great interest for the study of how situations of aggression and intimidation are motivated and developed. Group of equals has a very significant role as regulator of rules and norms of its culture. In bullying, studies [13] exposed and declared that the behaviors of the aggressors are strengthened with the help of the accompanying persons, who fundamentally develop the role of a spectator.

In all of this, the work and involvement of the teaching staff is very important, since they make crucial decisions in the integral formation of their students, participating in the elaboration of norms and habits of coexistence of plural and diverse complexity [14].

\section{ICT TOOLS FOR TACKLING BULLYING}

It is clear that there has been some relevant research on bullying as a social problem, with a special focus on schools and educational settings. With the increasing use of technology, there have been some researchers that have identified an opportunity to tackle bullying with the support of ICT tools. These tools provide different perspectives and strategies on how to fight against bullying, as well as showing 
different strengths and weaknesses. Therefore, they are different in nature. In this section, we review some relevant tools that have been proposed in the literature as a support for tackling bullying in schools. As these tools have different characteristics, we carry out a multidimensional analysis that aims to differentiate on the potential use of these tools. More specifically, we analyze the following dimensions:

- Role in the fight against bullying: An ICT tool may have different aims, and it may have been designed with some goals in mind. For instance, there are some tools whose role is that of educating students on the negative consequences of bullying, hence focusing on the role of prevention, while other tools may focus on proposing corrective actions against bullying once it has been identified (mitigation). In addition to this, there are tools that may focus on the early detection of bullying cases.

- Potential investment: Another important factor that may influence the adoption of an ICT tool is the potential investment needed by the educational institution. Depending on the type of application and technologies involved, it may require more or less investment on behalf of the school.

- Target students: The age and type of students also influences the applicability of a particular ICT tool. For instance, educational applications or games with childish characters may not be well received by teenagers. Similarly, tools that require complex interactions or tools that require more adult-like thinking may not be very effective with children.

- Strengths and weaknesses: Along with the aforementioned dimensions, we provide our point of view on the prospective strengths and weaknesses of each application.

FearNot! [15] is an immersive learning intervention tool whose role against bullying is helping victims to escape victimization, and to reduce overall bullying victimization among children. The tool consists of a virtual school populated by 3D avatars corresponding to students. Each student is associated with a role related to bullying (i.e. victims, bullies, bystanders). According to their roles, students respond to reallife bullying incidents. What is more, Artificial Intelligence techniques are included in order to learn from the victimization situations that students experience in order to adjust the efficacy of the system. This tool also considers gender characteristics. This causes that male situations include more physical bullying while female situations include more relational bullying. This tool was tested in 27 primary schools of UK and Germany during the year 2007-2008. In more detail, students aged between 7 and 11 years old participated in the study. These students did not receive any other specific anti-bullying intervention. According to the authors, they found some computer limitations and some technical problems when implementing the experiment, since some computers did not fit the specifications set in the intervention manual.

StopTheMob! [16] is a serious game whose aim is that of preventing bullying by means of an educational game. Students are immersed in a game situated in a fictional school, where they control several characters whose actions may have positive or negative consequences in the relationships among class members. The game provides a simple and fast learning curve, allowing younger students to effectively interact with the application. In fact, the application was tested with primary schools and characters depicted have a style that is oriented towards younger audiences. The game is executable on smart devices such as tablets, making it compulsory to invest in these devices if the game is aimed to be used in the classroom. The tool was satisfactory tested with a middle school. The game provides increasingly difficult scenarios, so that learners feel progression and increasingly face challenges. However, the game is static, and, every time, the game is the same for the user. This precludes the tool for being used repeatedly throughout an academic year.

Authors of [17] developed an application called PREVER for smartphones focused on bullying detection. PREVER is designed to involve not only students but also teachers. This application combines face-toface interaction among students with virtual interaction. The teacher supervises this interaction in order to detect negative behaviours. This application is designed for children under 16. It incorporates gamification techniques based on an augmented reality game. Basically, students see the classroom on their phones with augmented information related to their opponents in the application. Students freely interact with each other and the application collects data. In addition, the application also encourages interaction in order to motivate students to participate. What is more, this application deals with racial harassment.

Monité.org [18] is a video game that focuses on the prevention of bullying through the interactions of the main character with its universe. The game takes place in a universe conformed by different planets that is being terrorized by an evil villain. The game poses different situations to the main character that allow 
users to familiarize themselves with the psychological effects of bullying. In order to maximize the learning process of students, the application is aimed to be used under the supervision of teachers or parents. The target audience of this application are children between 5 and 10 years, as depicted characters have a fun and

Happy 8-12 and Happy 12-16 [19] are two applications designed to train emotional competences. These applications are focused to students between 8-12 years old, and 12-16 years old, respectively. These applications expose students to conflict situations and they should be able to respond in an assertive way. Similarly to FearNot!, these applications consider three different roles played by students: the person that shows an aggressive behaviour, the person that suffers the aggression, and bystanders. These applications consider 25 situations that are expected to train the students. Happy 8-12 was tested with almost 600 students and Happy 12-16 was tested with more than 900 .

Mii-School [20] consist of 17 3D scenes related to different situations, such as bullying, drug addiction or family life. This tool is focused on Secondary Education. In these situations, students are represented as avatars that interact with each other and they have to choose between different actions. Related to bullying, there are 5 scenes that approach bullying from different perspectives (e.g. as a victim, as a bully).

\section{DISCUSSION AND CONCLUSIONS}

As it can be observed, there are several ICT tools focused on bullying. In Table 1 we show a summary of the tools analyzed in previous section.

Table 1. Comparison of ICT tools for tackling bullying

\begin{tabular}{|l|l|l|l|l|}
\hline & Role & Investment & Target students & \multicolumn{1}{|c|}{ Strengths/Weaknesses } \\
\hline FearNot! & Mitigation & $\begin{array}{l}\text { Computers } \\
\text { with specific } \\
\text { requirements }\end{array}$ & $\begin{array}{l}\text { Primary schools } \\
(7-11 \text { yo) }\end{array}$ & $\begin{array}{l}\text { S: Al to adjust the tool and gender } \\
\text { W: Potential computer limitations and } \\
\text { technical problems }\end{array}$ \\
\hline StopTheMob! & Prevention & $\begin{array}{l}\text { Smart devices } \\
\text { for the } \\
\text { classroom }\end{array}$ & $\begin{array}{l}\text { Primary schools } \\
(7-11 \text { yo) }\end{array}$ & $\begin{array}{l}\text { S: Simple use, game-like environment } \\
\text { W: It does not allow repeated use } \\
\text { throughout the year }\end{array}$ \\
\hline PREVER & Detection & $\begin{array}{l}\text { Mobile } \\
\text { phones }\end{array}$ & Under 16 yo & $\begin{array}{l}\text { S: Racial harassment. Teacher can analyze } \\
\text { information } \\
\text { W: Face-to-face is required. Supervision of } \\
\text { the teacher is required. It may be difficult to } \\
\text { check whether actions are carried out or not }\end{array}$ \\
\hline $\begin{array}{l}\text { Happy 8-12 and } \\
\text { Happy 12-16 }\end{array}$ & Prevention & $\begin{array}{l}\text { Computers } \\
\text { with specific } \\
\text { requirements }\end{array}$ & $\begin{array}{l}\text { Primary schools } \\
(8-12 \text { yo) and } \\
\text { teenagers 12-16 } \\
\text { yo }\end{array}$ & $\begin{array}{l}\text { S: Easy to use and widely tested } \\
\text { W: Limited number of situations and few } \\
\text { adaptability }\end{array}$ \\
\hline Mii-School & Prevention & $\begin{array}{l}\text { Computers } \\
\text { with specific } \\
\text { requirements }\end{array}$ & $\begin{array}{l}\text { Secondary } \\
\text { schools }\end{array}$ & $\begin{array}{l}\text { S: 3D environment attractive to play } \\
\text { W: Limited functionalities. Efficiency not } \\
\text { widely tested }\end{array}$ \\
\hline
\end{tabular}

As it can be observed, most of the tools are oriented to train students by means of different virtual situations in which they show different behaviours (e.g. FearNot or Mii-School). These tools usually incorporate attractive graphics in order to motivate their use. Other tools such as PREVER are oriented to promote virtual and physical interaction among students, since interaction is crucial to fight against bullying. Some of the tools are focused on mobile applications, but the majority of them consist of a software that is installed on computers or other devices.

It can be also appreciated that the majority of the tools are oriented towards students. Some of them target Primary Education students (e.g. StopTheMob! or Happy 8-12), while others target Secondary Education students (e.g. Happy 12-16 or Mii-School). However, they are not usually thought of as applications targeting teachers and other academic staff. These groups are one of the main actors in the fight against bullying. Therefore, it is surprising that none of the analyzed tools focuses on providing decision-making support and bullying detection capabilities for academic staff. 
It can also be highlighted that most of the tools focus on prevention by means of educating students. Only two of the analyzed tools offer mitigation and detection capabilities. Detecting bullying is important, as it points out to the presence of problems in the classroom, as well as the prospective victims of bullying. We argue that, despite prevention mechanisms, some bullying problems may be inevitable. Thus, detecting bullying becomes as important as preventing bullying. Artificial Intelligence (Al) may play a very important role in detecting bullying among peers or, at least, potentially detecting individuals that may be victims of bullying. There have been some efforts on behalf of the Al community to provide algorithms that detect bullying on social networks [21]. While these efforts are incredibly valuable, there may be obstacles for application in a classroom. Social networks may be private, and educational institutions may not have access to the social networks or communication channels of their students. The next step and challenge for $\mathrm{Al}$ in this field should point towards detecting potential victims of bullying through inputs available in a classroom environment. As bullying may be inevitable, mitigation is also important. Once bullying has been perpetrated, teachers may need support to choose on the best strategies to follow in class to tackle the type of bullying that has been identified. ICT tools can be employed as decision support systems and guide teachers in the selection of these strategies based on expert knowledge and experience.

In conclusion, we have reviewed the negative impact of bullying on modern schools, as well as a range of ICT tools that are currently available for institutions to tackle bullying at different levels. Our analysis has identified that most tools focus on bullying prevention by means of educational applications. There is a need to propose ICT tools that support lecturers in the fight against bullying: both at the detection and mitigation stage. As bullying may be inevitable, tackling both mitigation and detection is as important as prevention. Our future work includes proposing ICT tools that provide lecturers with decision support mechanisms to both detect and mitigate bullying in a classroom.

\section{ACKNOWLEDGEMENTS}

This work has been partially funded by the Generalitat Valenciana (GV/2019/012).

\section{REFERENCES}

[1] Z. Staneva \& M. Molhova "The bullying phenomenon and the 'I am not scared' project in Bulgaria or how and why we need to influence the national school-education system". Psychology, Society, \& Education, 3(2), 147-157. 2011

[2] F. Cerezo-Ramírez "Psique: Bullying a través de las TIC". Boletín Científico Sapiens Research, 2(2), 24-29. 2012

[3] P. González Moreno, H. Gutiérrez Rodríguez, \& M. Checa Romero. "Percepción del maltrato entre iguales en educación infantil y primaria”. Revista de Educación(377), 136-160. 2017.

[4] R. Ortega-Ruíz \& F. Córdoba-Alcaide. "El modelo construir la convivència para prevenir el acoso y el ciberacoso escolar". Innovación Educativa, 27, 19-32. 2017.

[5] A. B. Górriz Plumed "Roles implicados en el acoso escolar: comprensión de la mente, maquiavelismo y evitación de responsabilidad. Psicología Evolutiva, Educativa, Social y Metodología". PhD. Thesisl, Facultad de Ciencias Humanas y Sociales, Universitat Jaume I de Castellón. 2009.

[6] A. Gómez Sanabria, F.J. Gala, M. Lupiani, A. Bernalte, M. T. Miret, S. Lupiani \& M.C. Barreto. "EI "bullying" y otras formas de violencia adolescente". Cuadernos de Medicina Forense, 13(48-49), 165-177. 2007.

[7] A. Serrano. "Acoso y Violencia en la escuela. Como detectar, prevenir y resolver el bullying". Barcelona: Ariel.

[8] D. Olweus. "Conductas de acoso y amenaza entre escolares". Morata. 1989.

[9] C. Salmivalli. "Participant role approach to school bullying: implications for interventions". Journal of Adolescence, 22, 453-459. 1999.

[10] J.D. Coie, K. A., Dodge, R. Terry \& V. Wright. "The Role of Aggression in Peer Relations: An Analysis of Aggression Episodes in Boys' Play Groups". Child Development, 62(4), 812-826. 1991. 
[11] C. F. Garandeau \& A.H.N. Cillessen. "From indirect aggression to invisible aggression: A conceptual view on bullying and peer group manipulation". Aggression and Violent Behavior, 11(6), 612-625. 2006

[12] A. D. Pellegrini \& J. D. Long. "A longitudinal study of bullying, dominance, and victimization during the transition from primary school through secondary school". British Journal of Developmental Psychology, 20(2), 259-280. 2002

[13] R.W. Solomon, \& R.G. Wahler. "Peer reinforcement of classroom problem behavior". Journal of Applied Behavior Analysis, 6, 49-56. 1973.

[14] A. Peñalva, J.J. López-Goñi, A. Vega-Osés \& C. Satrústegui. "Clima escolar y percepciones del profesorado tras la implementación de un programa de convivencia escolar". Estudios sobre Educación, 28, 9-28. 2015.

[15] M. Sapouna, D. Wolke, N. Vannini, S. Watson, S. Woods, W. Schneider \& K. Dautenhahn. "Virtual learning intervention to reduce bullying victimization in primary school: a controlled trial". Journal of Child Psychology and Psychiatry, 51(1), 104-112. 2010

[16] C.S. Walsh \& A. Schmoelz. "Stop the Mob! Pre-service teachers designing a serious game to challenge bullying". In International Conference on Games and Learning Alliance (pp. 431-440). Springer, Cham. 2015

[17] J.A. Álvarez-Bermejo, L.J. Belmonte-Ureña, A. Martos-Martínez, A.B. Barragán-Martín \& M. del Mar Simón-Marquez. "System to detect racial-based bullying through gamification". Frontiers in psychology, 7, 1791. 2016

[18] U. Diaz-Orueta. "Serious games and gamified tools for psychological intervention: a review". In Integrating Technology in Positive Psychology Practice (pp. 290-314). IGI Global. 2016

[19] A. Ros Morente, E. Cabello, \& G. Filella Guiu. "Analysis of the Effects of two Gamified Emotional Education Software's in Emotional and Well-being Variables in Spanish Children and Adolescents". International Journal of Emerging Technologies in Learning, 2018, vol. 13, núm. 9, p. 148-159. 2018

[20] J.A. Carmona, M. Espínola, A.J Cangas \& L. Iribarne. "MII-School: A 3d videogame for the early detection of abuse of substances, bullying, and mental disorders in adolescents". European Journal of Education and Psychology, 4(1), 75-84. 2011

[21] K. Dinakar, R. Reichart \& H. Lieberman. "Modeling the detection of textual cyberbullying". In fifth international AAAl conference on weblogs and social media. 2011 